Available online at www.sciencedirect.com

\title{
Colour biases are a question of taste
}

\author{
CANDY ROWE \& JOHN SKELHORN \\ School of Biology, University of Newcastle \\ (Received 9 December 2003; initial acceptance 3 February 2004; \\ final acceptance 6 June 2004; published online $\mathbf{\square} \mathbf{\square}$; MS. number: 7928)
}

\begin{abstract}
Unpalatable insects often advertise their defences to avian predators by conspicuous colours, such as red and yellow. Therefore, perhaps not surprisingly, birds tend to have unlearned biases against warningly coloured food. These biases are particularly evident when other components of insect warning displays, such as novel sounds and odours, are also present. We tested whether bitter taste, often associated with the defensive chemicals used by aposematic insects, can elicit or enhance specific colour aversions to red and yellow food in young domestic chicks, Gallus gallus domesticus. In our first experiment, subjects were given familiar brown chick crumbs sprayed with either a 0,1 , or $4 \%$ quinine solution. In each palatability treatment, chicks were then offered a choice of palatable crumbs that were coloured either red and green or yellow and green. Chicks attacked (pecked or ate) fewer red and yellow crumbs and more green crumbs with increasing quinine concentrations. Chicks also ate fewer red and yellow crumbs with increasing unpalatability, although there was no effect on the numbers of green crumbs eaten. In a second experiment, we gave chicks a colourless drop of either 0 or $0.3 \%$ quinine solution and found that this also produced similar attack biases against red and yellow as is in the first experiment. Taken together, these results show that birds use unpalatable taste to adapt their visual foraging decisions, which has consequences for the evolution and stability of mimicry systems, and also has implications for the pairing of colour and taste in psychological experiments.
\end{abstract}

(c) 2005 The Association for the Study of Animal Behaviour. Published by Elsevier Ltd. All rights reserved.

Aposematic insects use conspicuous colour patterns to advertise their unpalatability to potential avian predators (Poulton 1890; Cott 1940). Stinging apparatus (e.g. Möstler 1935), incapacitating toxins (e.g. Brower et al. 1968) and noxious taste (e.g. Steiniger 1937) have all been shown to be effective means of defence in insects, and birds can learn to avoid insects possessing them on the basis of their visual appearance. The conspicuous colour patterns used by aposematic insects, such as the yellow and black stripes of vespids and the red and black patterns of coccinellids, are thought to speed up the avoidance learning process by being particularly salient to birds (Gittleman \& Harvey 1980; Roper \& Wistow 1986; Guilford 1992). In addition, many studies have shown that birds can have unlearned aversions to particular colours and patterns associated with warning signals (e.g. Schuler \& Hesse 1985; Sillén-Tullberg 1985; Roper \& Cook 1989; Mastrota \& Mench 1995; see Schuler \& Roper 1992 for review), although the results of these studies are not always consistent (e.g. Fischer et al. 1975; Roper 1990; Roper \& Marples 1997b; Jones \& Carmichael 1998).

Correspondence: C. Rowe, School of Biology, University of Newcastle, Henry Wellcome Building for Neuroecology, Framlington Place, Newcastle upon Tyne NE2 4HH, U.K. (email: candy.rowe@ncl.ac.uk).
In nature, the warning displays of many aposematic insects rarely depend on coloration alone, and many insects use sounds and odours as part of their displays (Cott 1940; Haskell 1966; Edmunds 1974a). It was thought that these additional signal components acted to enhance the speed of association between coloration and unpalatability (Claridge 1974; Rothschild et al. 1984), but while there is some evidence that sounds may improve colour discrimination learning (Rowe 2002), there is no evidence that odours do so (Rowe \& Guilford 1996; Rowe 1998; but see Roper \& Marples 1997a for data showing an interaction between colour and odour in a learning experiment). However, the presentation of a novel sound or odour consistently causes naïve foraging chicks to bias their behaviour against food with visual traits associated with aposematism, such as food that is conspicuous, red or yellow, or novel (Marples \& Roper 1996; Rowe \& Guilford 1996, 1999a, b; Jetz et al. 2001; Lindström et al. 2001). The results from these experiments show how signal components in other sensory modalities can change colour preferences in birds in a way advantageous to both predator and prey (reviewed in Rowe \& Guilford 1999b).

We extended this idea by looking at whether taste itself can change colour biases in an adaptive fashion in young birds (Rowe \& Guilford 1999b). Unpalatability is often thought to deter birds on the basis of its unpleasantness, 
but birds sampling prey may also use it as an additional signal of underlying toxins (reviewed in Brower 1984; Nishida 2002). There is some evidence that birds reject prey on the basis of taste (e.g. beak marks in butterfly wings; Edmunds 1974b; Smith 1979; but see Kassarov 1999 for an alternative view), but birds could also be using taste cues in conjunction with visual information in making their foraging decisions. There is some evidence from one study that unpalatability evokes colour biases in foraging birds. Adult quail, Coturnix coturnix japonica, readily attacked black palatable beetles that carried the taste of seven-spot ladybirds, Coccinella septempunctata, but when the red and black elytra were added to the beetles, the rate of rejection increased dramatically (Marples et al. 1994). Although the experiment did not test it explicitly, these data lend themselves to the idea that taste can promote specific colour aversions (i.e. against red and black patterns, but not against black).

We conducted two experiments that tested the effect of taste on colour preferences of naïve domestic chicks, Gallus gallus domesticus. In both experiments, we gave separate groups of chicks a choice between 30 green crumbs and either 30 yellow crumbs or 30 red crumbs. For simplicity, throughout the paper we refer to the yellow and red crumbs as being 'warningly coloured' since these are colours commonly associated with aposematic insects, with green being associated more with palatable cryptic prey. We discuss this assumption below.

\section{EXPERIMENT 1: QUININE-FLAVOURED FOOD}

\section{Subjects and Housing}

We hatched 79 chicks (Goldline strain) from a single batch of eggs obtained from a commercial hatchery in June 2003. The chicks were of mixed sex and hatched over 2 days; 42 hatched on the first day and 37 on the second. Chicks were kept in two laboratories; on each hatch date, they were split between the two rooms so that there were similar numbers of males and females in each. They were kept in cages (ca. $50 \times 100 \mathrm{~cm}$ and $50 \mathrm{~cm}$ high), and chicks hatched on separate days were housed in different cages (there were therefore four cages housing 18-22 chicks each). All subjects were marked with nontoxic 'child-friendly' coloured marker pens, which did not appear to have any adverse effects on chick behaviour. Water and brown chick starter crumbs were provided ad libitum except during food deprivation periods before testing, when crumbs were removed. Chicks were kept at approximately $23-25^{\circ} \mathrm{C}$ using heat lamps and on a 14:10 h light:dark cycle under uncovered fluorescent tubing. Weights of experimental birds were monitored daily, and chicks were rehoused at small free-range holdings after the experiment.

\section{Training}

Although the chicks were split by hatch date, the training regimes of chicks hatched on each of the 2 days were the same, that is, the first half of the hatch were trained and tested 1 day ahead of the second half. For each hatch date, we consider the day of hatching as day 0 , and all training days relate to this reference day for both sets of chicks. The training was carried out in each of the laboratories where the chicks were housed, and the regime in each room was the same but was carried out by different experimenters.

On day 1 posthatch, chicks were put into the experimental arena in triplets to acclimatize. We used a circular walled arena (diameter $1 \mathrm{~m}$, walls $25 \mathrm{~cm}$ high) with a white floor upon which brown chick starter crumbs were scattered. Chicks were allowed to forage in this arena for 5-10 min and received two further trials of this type on day 1 separated by approximately $2 \mathrm{~h}$. On day 2 , chicks were deprived of food for $1-2 \mathrm{~h}$ before testing. This deprivation period did not seem to distress the chicks (none distress called, perhaps because food often still remained in their crops) nor to have any adverse effects on their daily weight increases. They then received three trials; for the first two of these, chicks were put in the arena in pairs for $10 \mathrm{~min}$ at a time, and in the final trial were put in singly for approximately $5 \mathrm{~min}$. Chicks were not distressed by this training regime and all readily ate food from the arena by the end of day 2 . On day 3 , subjects were again food deprived for $1-2 \mathrm{~h}$, and then given two further trials of approximately $5 \mathrm{~min}$ alone in the arena to ensure that they were familiar with the apparatus and readily ate upon being put in it. All chicks readily ate in the arena on day 3 , which allowed us to use all the hatched chicks independently for data collection, thus reducing the total number of birds required for the experiment.

\section{Testing}

On day 4 posthatch, we randomly assigned chicks to one of six experimental groups. There were two colour treatments: approximately half the chicks on each day received 30 red and 30 green crumbs scattered in the arena, and the rest received 30 yellow and 30 green crumbs. The crumbs were dyed with commercially produced nontoxic food dyes diluted to various concentrations to produce crumbs of similar saturation. We used $0.2 \mathrm{ml}$ of 'Sugar Flair' spruce green colouring, $2 \mathrm{ml}$ of 'Supercook' red colouring and $5 \mathrm{ml}$ 'Supercook' yellow colouring, all diluted to $90 \mathrm{ml}$ with water. (These concentrations produced comparable saturation of each colour to our eyes; we used a more dilute solution of the green dye because it was a much stronger commercial dye than that of the red or the yellow.) Each solution was added, by syringe, to $150 \mathrm{~g}$ of brown chick starter crumbs and left to dry for $24 \mathrm{~h}$. They were then sieved to get crumbs of a similar size. These crumbs were randomly scattered in the front two-thirds of the arena.

Each chick was put singly into the back third of the arena where they immediately encountered three brown starter crumbs (we put the chicks by the food to ensure that this was the first food that they attacked). These crumbs were soaked and sieved in a similar manner to the 
coloured crumbs, except that they were not coloured but were flavoured with either 0,1 or $4 \%$ quinine solution (100 ml of each quinine solution was sprayed on to $150 \mathrm{~g}$ of brown chick starter crumbs). (Previous experiments showed that chicks can taste this aversant since they can learn to discriminate between coloured crumbs when one colour is flavoured with 1 or $4 \%$ quinine solution, unpublished data.) All chicks readily attacked these three crumbs first when put in the arena, although four chicks ate only two of their crumbs and pecked and rejected their third crumb (all these cases were when the brown crumbs were unpalatable; three in the $4 \%$ treatments, and one in a $1 \%$ treatment). After attacking the three brown crumbs, chicks were allowed to attack (peck or eat) 16 of the 60 coloured crumbs before being removed from the arena. In the test trial, 34 of the 79 chicks called at some point in response to the novel situation. However, no chick called for more than half of a trial and all birds continued to forage.

For each hatch date, we put approximately equal numbers of chicks from each colour treatment into one of these three quinine treatments to create the six experimental treatments: Yellow- $0 \%(N=13)$, Yellow$1 \%(N=13)$, Yellow-4\% $(N=13)$, Red-0\% $(N=13)$, Red-1\% $(N=14)$ and Red- $4 \%(N=13)$. The groups were balanced as far as possible between the experimental rooms and by the sex of the chicks. In each laboratory, chicks from one colour treatment were tested before the other on the first day (red was first in one laboratory and yellow in the other), and the order was reversed for the following day. Within each colour treatment, chicks from different quinine groups were tested in a random order.

\section{Results}

All chicks attacked 16 crumbs in the test trial on day 4 . An attack was either pecking or eating a crumb since both these behaviours show a clear food choice. All birds attacked at least one green crumb; those given yellow crumbs all attacked at least one of these, and all but three chicks given red crumbs attacked at least one red crumb (two were in the $0 \%$ quinine group and one was in the $4 \%$ quinine group). We analysed the number of attacks made by each chick on warningly coloured crumbs (yellow or red depending on the treatment) with a general linear model ANOVA (SPSS V. 11, SPSS Inc., Chicago, U.S.A.). In this model we included the treatments of colour and quinine, and the colour $\times$ quinine interaction; we also included the sex of the chick and the laboratory in which they were tested (as fixed factors), and hatch date and colour order (as random factors). There were significant main effects of both quinine concentration and crumb colour on the number of warningly coloured crumbs attacked (Table 1). In general, chicks attacked fewer red crumbs than yellow crumbs, and for both crumb colours attacks on yellow and red crumbs consistently declined with increasing quinine concentration (Fig. 1a). There were no other significant effects from any other factor or interaction $(P>0.4$ for all tests; Table 1$)$.

Although all chicks attacked 16 crumbs, the numbers that they actually ate varied between 0 and 13 for green crumbs, and between 0 and 9 for both yellow and red crumbs. Only four chicks did not eat any food in the trial (they only pecked at the crumbs): one was in the Red-0\% group, one was in the Red-4\% group and two were from the Yellow-4\% group. We therefore separately analysed the number of green crumbs and the numbers of warningly coloured crumbs that each group ate during the test trial to look for effects of colour and quinine on their consumption (Fig. 1b). (Data for the green crumbs had to be squareroot transformed and those for warningly coloured crumbs log transformed to meet the assumptions of the ANOVA.) With the same model as before, the only significant effect on the consumption of green crumbs was the colour of the alternative crumb (Table 1), with more green crumbs being eaten when red was the alternative colour than when it was yellow. Overall levels of consumption of the warningly coloured crumbs were affected by their colour, but also by what quinine concentration had been used (Fig. 1b): there was no colour $\times$ quinine interaction. The only other significant effect was which room the chicks had been tested in. These analyses show that quinine reduced only the number of warningly coloured crumbs eaten and not the number of green eaten.

Table 1. Results from the general linear models testing differences between the groups in experiment 1

\begin{tabular}{|c|c|c|c|c|c|c|c|}
\hline \multirow[b]{2}{*}{ Factor } & \multirow[b]{2}{*}{$d f$} & \multicolumn{2}{|c|}{$\mathrm{Y} / \mathrm{R}$ attacks } & \multicolumn{2}{|c|}{$\mathrm{G}$ eaten } & \multicolumn{2}{|c|}{ Y/R eaten } \\
\hline & & $F$ & $P$ & $F$ & $P$ & $F$ & $P$ \\
\hline Quinine & 2,69 & 9.65 & 0.00 & 0.46 & 0.64 & 3.58 & 0.03 \\
\hline Colour & 1,69 & $3 \overline{7.68}$ & $\overline{0.00}$ & 4.28 & 0.04 & $3 \overline{2.57}$ & $\overline{0.00}$ \\
\hline Quinine $*$ colour & 2,69 & 0.69 & 0.51 & $\overline{1.73}$ & 0.18 & 0.61 & $\overline{0.55}$ \\
\hline Sex & 1,69 & 0.15 & 0.70 & 0.00 & 0.96 & 0.80 & 0.38 \\
\hline Laboratory & 1,69 & 0.18 & 0.67 & 2.39 & 0.13 & 6.18 & 0.02 \\
\hline Hatch date & 1,69 & 0.39 & 0.53 & 3.06 & 0.09 & $\overline{1.08}$ & $\overline{0.30}$ \\
\hline Colour order & 1,69 & 0.50 & 0.48 & 0.03 & 0.88 & 1.50 & 0.22 \\
\hline
\end{tabular}

The $F$ and $P$ values are given for the following three tests: the number of attacks made on yellow or red crumbs (Y/R attacks); the number of green crumbs eaten (square-root transformed data) ( $\mathrm{G}$ eaten); and the number of yellow or red crumbs eaten (log-transformed data) ( $\mathrm{Y} / \mathrm{R}$ eaten). Quinine, colour, sex and laboratory were all fixed factors in the model, while hatch date and colour order were random factors. Underlined values show significant effects. 

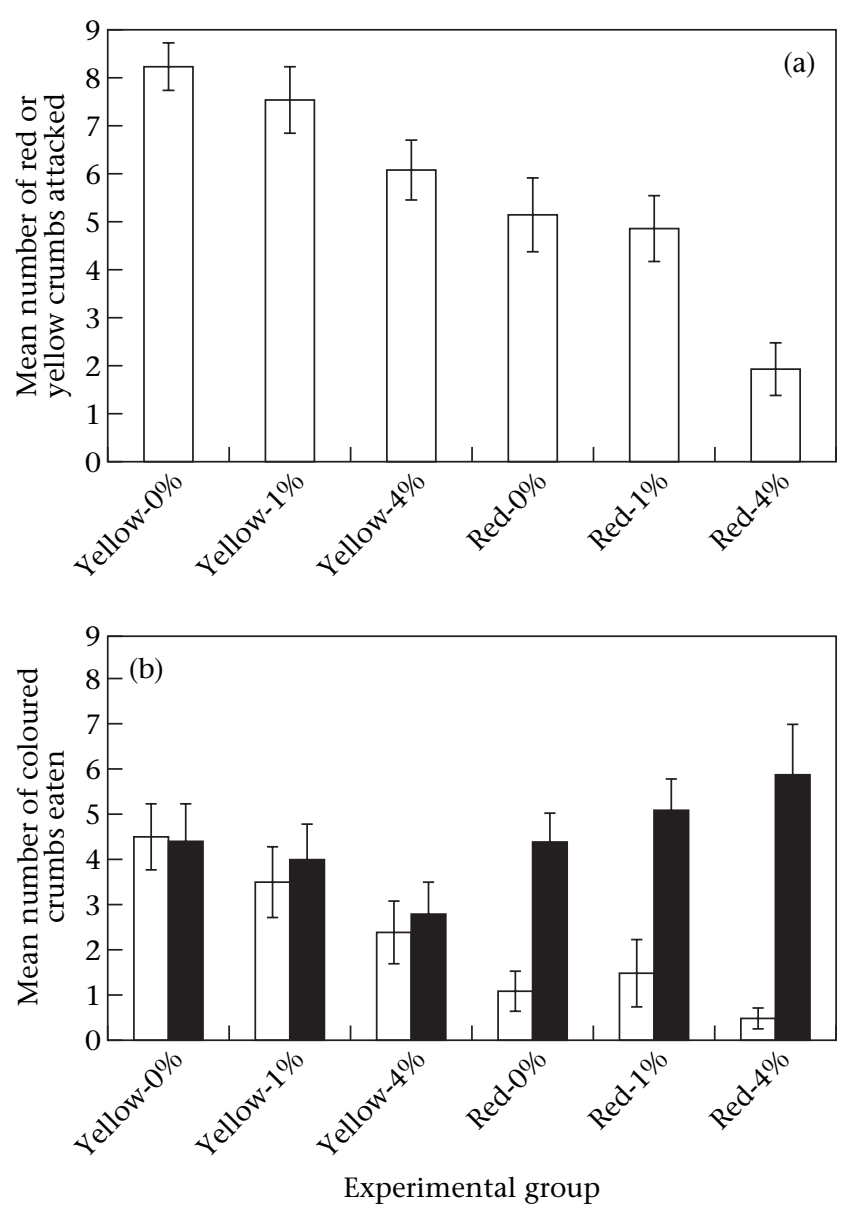

Figure 1. The results from experiment 1 where chicks received green crumbs and either red or yellow crumbs after ingesting crumbs flavoured with 0,1 or $4 \%$ quinine solution: (a) mean \pm SE number of red or yellow crumbs attacked by each experimental group, and (b) mean \pm SE number of red or yellow crumbs ( $\square$ ) and green crumbs ( $\mathbf{\square})$ eaten by each group.

\section{Discussion}

When quinine was given to chicks on brown chick crumbs before the colour preference task, chicks biased their attacks away from those colours typically associated with insect warning patterns (red and yellow) and towards food of a more neutral colour (green). The bias was stronger when the warning colour was red than when it was yellow. This attack bias parallels those seen when chicks are given an odour or a sound alongside a colour preference task (Marples \& Roper 1996; Rowe \& Guilford 1996, 1999b; Jetz et al. 2001; Lindström et al. 2001). In addition, chicks ate fewer red and yellow crumbs after quinine presentation, although the number of green crumbs eaten was unaffected. However, the numbers of warningly coloured and green prey eaten were both affected by whether the warning colour was red or yellow: chicks ate fewer warningly coloured crumbs and more green crumbs when the warning colour was red (Fig. 1b). Therefore, as with the attack biases, the reduction in the numbers of warningly coloured crumbs eaten was greater when the crumbs were red than when they were yellow.
The increase in the number of green crumbs eaten in the red groups may have counterbalanced the reduced consumption of red crumbs given that all chicks had a similar hunger level during testing.

Although there were differences between the red and yellow groups in the strengths of the effect, the pattern of behaviour seems to be the same, with quinine eliciting unlearned biases against red and yellow food. However, an alternative explanation exists: chicks may have biased their behaviour because they associated the unpalatability with the brown crumbs, and they generalized to avoid red and yellow crumbs more than green. To rule out the possibility that the avoidance was learned, we repeated the experiment, removing any potential colour association with the quinine by using a clear quinine solution.

\section{EXPERIMENT 2: QUININE-FLAVOURED WATER}

\section{Subjects and Housing}

We hatched 50 domestic chicks from a single batch of eggs obtained from the same commercial hatchery in October 2003. The chicks were of mixed sex and hatched in a single day. They were kept in the same two laboratories, and were split between them so that there were similar numbers of males and females in each. Holding conditions were the same as in the previous experiment, with 25 chicks in each cage in each room.

\section{Training}

The training was the same as that for experiment 1 , with the training being carried out in each of the laboratories where the chicks were housed by different experimenters. By the end of day 3, 47 chicks ate on their own in the arenas and showed no signs of distress.

\section{Testing}

On day 4 posthatch, chicks were randomly assigned to one of four experimental groups. There were two colour treatments: approximately half the chicks on each day received 30 red and 30 green crumbs scattered in the arena, and the other half received 30 yellow and 30 green crumbs. Approximately equal numbers of chicks in each colour treatment were put into either a control group that received a single drop of distilled water from a 20-100 $\mu \mathrm{l}$ micropipette, or a quinine group where they were offered a drop of $0.3 \%$ quinine solution. The concentration of the quinine solution we used here was much less than that used in the previous experiment because of the apparent differences in taste intensity between the dry and the liquid form. We chose this particular concentration because of its similar unpalatability (to us) as the $4 \%$ quinine-flavoured crumbs. We gave the drop of water or quinine solution either by offering it from the end of the micropipette (from which many chicks readily drank) or by putting a drop of the solution on the end of the beak while the chick was in the home cage. Chicks were able to 
drink the drop from the end of their beaks, or shake their heads and wipe it off. Four chicks refused to drink the drop given to them and could not be included in the experiment. After chicks had tasted the solution they had been given, they were put into the arena and allowed to attack (peck or eat) 16 coloured crumbs before being returned to their home cage. Again, some of the chicks called during the test trial (18/43), but no chick called for more than half the trial and all chicks continued to forage.

Therefore, there were four experimental groups, balanced as far as possible between rooms and by the sex of the chicks: Yellow-0\% $(N=10)$, Yellow-0.3\% $(N=10)$, Red-0\% $(N=12)$ and Red- $0.3 \%(N=11)$. In one room, birds given the yellow/green choice were tested before those given the red/green colour choice, and in the other this order was reversed. Chicks were tested in a random order within their colour treatment.

\section{Results}

All 43 chicks attacked 16 crumbs, and their choices once again showed a strong effect of quinine on colour preference (Fig. 2). We analysed the number of attacks made on red or yellow crumbs (depending on treatment) using a general linear model ANOVA, where we included the same factors as before: colour, quinine, the colour $X$ quinine interaction, sex, the laboratory in which they were tested (all as fixed factors), and whether they were in the first half of the chicks tested or in the second half (a random factor). As in experiment 1 , quinine significantly biased the number of attacks away from warningly coloured crumbs in favour of green crumbs (Fig. 2a). Chicks also attacked fewer warningly coloured crumbs when they were red than when they were yellow. No other factor or interaction was significant (Table 2).

As for the previous experiment, we also analysed the number of coloured crumbs that were consumed by chicks to see if there was a similar bias in the numbers eaten. The number of coloured crumbs eaten was lower in this experiment than in experiment 1: the number of green crumbs eaten was $0-12$, the number of yellow crumbs $0-4$ and the number of red crumbs $0-3$. In addition, eight chicks did not eat any crumbs, although these were distributed fairly evenly across the experimental groups: two in group Yellow-0\%, one in group Yellow-0.3\%, three in group Red-0\% and two in group Red-0.3\%. Using the same ANOVA model, we analysed the number of green crumbs eaten and the numbers of red and yellow crumbs eaten by each group separately (Fig. 2b). While there was no significant effect of any factor on the number of green crumbs eaten (Table 2), chicks ate fewer warningly coloured crumbs when they were red than they were yellow. There was no effect of quinine on the numbers of red and yellow crumbs eaten, and no other factor or interaction was significant (Table 2).

\section{Discussion}

These data confirm the results from experiment 1 showing that unpalatability (here in the form of quinine
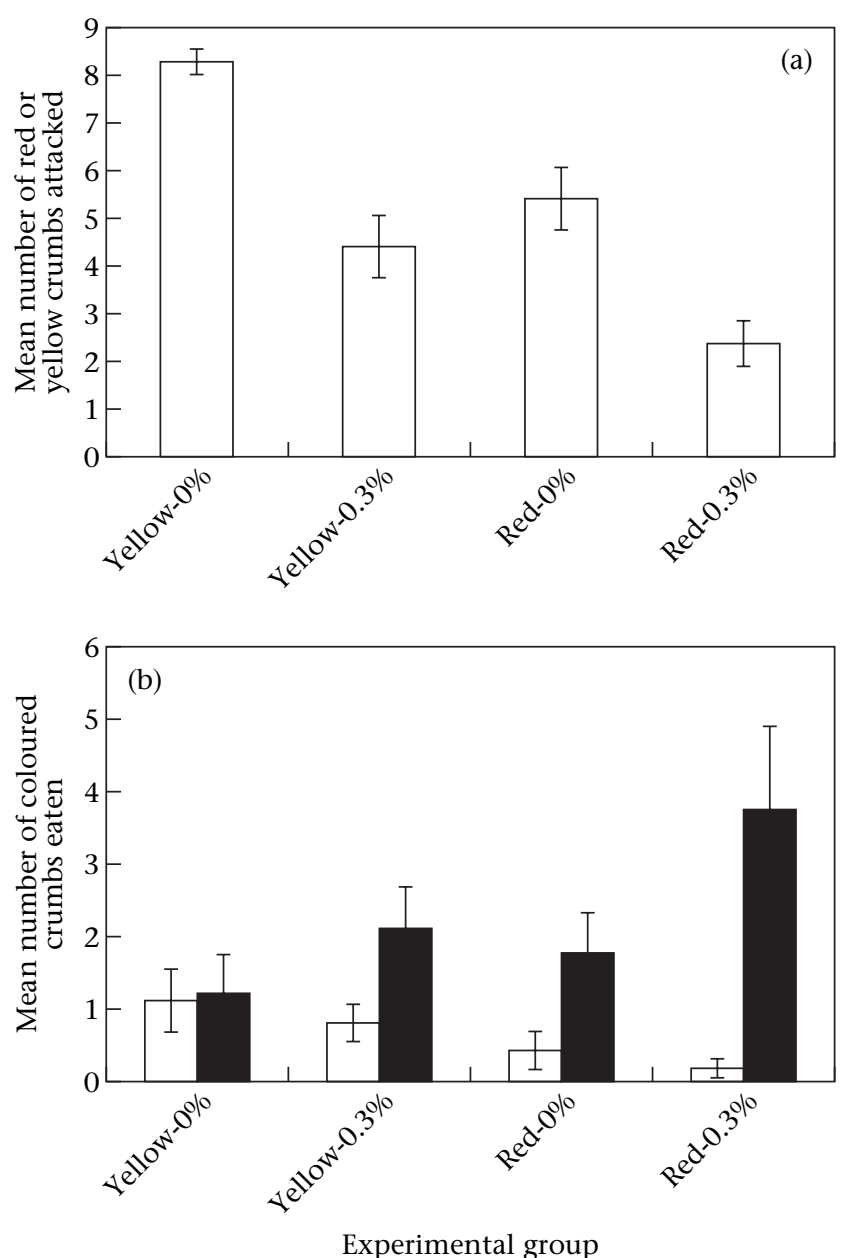

Figure 2. The results from experiment 2 where chicks received green crumbs and either red or yellow crumbs after tasting a drop of 0 or $0.3 \%$ quinine solution: (a) mean $\pm \mathrm{SE}$ number of red or yellow crumbs attacked by each experimental group, and (b) mean $\pm \mathrm{SE}$ number of red or yellow crumbs $(\square)$ and green crumbs ( $\square$ ) eaten by each group.

sulphate solution) can elicit or enhance colour attack biases in young domestic chicks. The finding that unpalatability skews the attack rates on coloured crumbs in favour of green and away from red and yellow crumbs was highly significant in both experiments. However, unlike in experiment 1 , in this experiment we did not find a significant effect of quinine on the numbers of red and yellow crumbs consumed, although the data in Fig. 2b suggest a similar pattern to that in experiment 1 . Failure to replicate this effect might have been caused by the low number of warningly coloured crumbs consumed in this particular experiment. Consistent with the first experiments, chicks did not show an attack bias against yellow crumbs in the absence of quinine: it became evident only when they tasted the quinine solution. Chicks did show an attack bias against red crumbs without quinine present, but this was even greater after presentation with quinine solution. Although the quinine solution used was much weaker than the solutions sprayed on the crumbs in experiment 1, it elicited biases similar to those of chicks 
Table 2. Results from the general linear models testing differences between the groups in experiment 2

\begin{tabular}{|c|c|c|c|c|c|c|c|}
\hline \multirow[b]{2}{*}{ Factor } & \multirow[b]{2}{*}{$d f$} & \multicolumn{2}{|c|}{$\mathrm{Y} / \mathrm{R}$ attacks } & \multicolumn{2}{|c|}{ G eaten } & \multicolumn{2}{|c|}{ Y/R eaten } \\
\hline & & $F$ & $P$ & $F$ & $P$ & $F$ & $P$ \\
\hline Quinine & 1,36 & 42.66 & 0.00 & 2.94 & 0.10 & 0.83 & 0.37 \\
\hline Colour & 1,36 & 22.86 & $\overline{0.00}$ & 2.07 & 0.16 & 4.89 & 0.03 \\
\hline Quinine $*$ colour & 1,36 & 0.38 & $\overline{0.54}$ & 0.74 & 0.40 & $\overline{0.04}$ & $\overline{0.85}$ \\
\hline Sex & 1,36 & 0.00 & 0.96 & 1.82 & 0.19 & 0.28 & 0.60 \\
\hline Laboratory & 1,36 & 0.80 & 0.38 & 0.05 & 0.83 & 1.00 & 0.75 \\
\hline Test order & 1,36 & 4.00 & 0.053 & 0.39 & 0.54 & 0.34 & 0.56 \\
\hline
\end{tabular}

The $F$ and $P$ values are given for the following three tests: the number of attacks made on yellow or red crumbs (Y/R attacks); the number of green crumbs eaten (square-root transformed data) ( $\mathrm{G}$ eaten); and the number of yellow or red crumbs eaten (log-transformed data) ( $\mathrm{Y} / \mathrm{R}$ eaten). Quinine, colour, sex and laboratory were all fixed factors in the model, while hatch date and colour order were random factors. Underlined values show significant effects.

that had been given brown crumbs sprayed with a $4 \%$ quinine solution. This shows that less quinine sulphate is required in liquid form than in solid form to be an effective aversant perhaps because the quinine is already soluble, and because it is a liquid, more receptors are stimulated in the oral cavity than would be by a single crumb (Kassarov 1999). We chose these two concentrations because they tasted similar to us, and it may be that birds have similar judgements of taste.

\section{GENERAL DISCUSSION}

These experiments clearly show that exposure to an unpalatable chemical can affect subsequent colour preferences towards novel food in young foraging birds. This confirms the idea that taste and colour interact in inducing visual biases (Rowe \& Guilford 1999b), which was originally suggested by the data of Marples et al. (1994). It is impossible to tell from the attack data whether the chicks' preferences increased for green or decreased for red and yellow, or whether there was a combination of these two changes in preference. However, the analysis on the number of coloured crumbs eaten in experiment 1 suggests that increasing unpalatability reduced the number of red and yellow crumbs eaten, but did not affect the number of green crumbs eaten. Experiment 2 also shows that quinine did not affect the number of green crumbs eaten, but in this case the numbers of red and yellow crumbs were not affected. This could have been caused by the small numbers of red and yellow crumbs eaten in this experiment, as the data suggest a similar pattern to that of experiment 1 (compare Figs $1 \mathrm{~b}$ and $2 \mathrm{~b}$ ). This suggests that the result was produced by a bias against red and yellow food rather than an increased preference for green. This tendency for naïve avian predators, such as chicks, to bias their choices against red and yellow food could be adaptive in nature, with bad-tasting warningly coloured insects benefiting from increased survival.

So far we have referred to yellow and red crumbs as 'warningly coloured' in an attempt to simplify the explanation of our experiment. Of course, there is no guarantee that the chicks perceived the colours exactly as we do, or that they associated the specific colours with being a warning signal. Colour perception differs between humans and birds, and in particular avian vision extends into the ultraviolet (UV) range of the spectrum (e.g. Cuthill et al. 2000). In this experiment, birds were not using any UV cues because the fluorescent lighting does not produce any light in the UV range. We acknowledge that the biases seen here could be caused by the specific colours that we used, but the consistency with other studies (e.g. Rowe \& Guilford 1996; Gamberale-Stille \& Tullberg 2001; Jetz et al. 2001) suggests that it is the association of these colours with warning signals in the wild that is likely to be important in the decision-making process.

Similar colour preference changes have been seen by presenting other cues in different sensory modalities alongside a colour choice. Pyrazine, an odour commonly produced by aposematically coloured insects, also elicited the same unlearned biases against yellow and red food and towards green food when presented in the same room as the choice test, although in that case the relative aversion to yellow was much stronger than that to red (Rowe \& Guilford 1996). Pyrazine odour can also produce biases against other visual attributes associated with aposematic prey, such as being conspicuous (Lindström et al. 2001) or novel (Marples \& Roper 1996; Jetz et al. 2001). In addition, the buzzing of a bumblebee, Bombus terrestris, can also produce a relative bias against yellow food in chicks, and also enhance neophobia to novel-coloured food (Rowe \& Guilford 1999b). One common feature to these studies is that the odours and sounds were novel, and odour novelty is important in eliciting colour biases (Rowe \& Guilford 1999a). It could therefore be the novelty of the quinine solution that is important in producing the colour biases: this may even encourage diversity in defensive chemicals. However, whether it is the novelty of the taste or the taste itself that produces the bias, this result leads us to question whether taste should be viewed as an additional signal component of underlying toxicity rather than as a deterrent that works in the same way as a toxic chemical (Brower 1984).

This is an interesting question since the ethological approach to aversion learning of warning coloration predominantly assumes that unpalatable taste is equivalent to toxicity as a negative reinforcer (e.g. Shettleworth 
1972; Gittleman \& Harvey 1980; Roper \& Wistow 1986). Although unpalatability may correlate with toxicity in nature and be a reliable signal of toxicity, aversions through illness may differ qualitatively from those based just on taste (Testa \& Ternes 1970; Cowan et al. 2000). Experimental psychologists commonly use taste as a cue that animals can use to avoid ingesting toxic substances (usually lithium chloride injections; e.g. Hayne et al. 1996; Franchina et al. 1997), which might produce results that are more applicable to the natural situation. Contrary to the conjecture that birds have a very poor sense of taste (Kassarov 1999), psychology experiments have shown that taste can reduce the intake of substances that are visually novel (Franchina et al. 1997), and also potentiate the colour-toxin association so that colours are associated more strongly with illness if bad taste is present (Clarke et al. 1979; Lett 1980; Westbrook et al. 1980; Franchina et al. 1997). These learning experiments therefore use taste and colours as stimuli that predict aversive consequences (i.e. acting as a conditioned stimulus, or CS) rather than being aversive themselves (i.e. acting as an unconditioned stimulus, or US). Psychologists have not investigated whether the strength of the learned avoidance is dependent on the colour or taste quality used as the conditioned stimulus, but we would predict that bitter tastes might promote the largest aversions to visual cues, especially if they are warningly coloured.

The specificity of the taste-colour association is interesting, and it is not clear how the bias seen in this experiment would affect the learning process. In a now classic experiment, Garcia \& Koelling (1966) showed that rats, Rattus norvegicus, readily associated taste with illness and an audiovisual cue with an electric shock, but found it difficult to associate taste with an electric shock and the audiovisual cue with sickness. This predisposition to associate negative effects with the cues that are most likely to predict them is advantageous to animals in avoiding future bad encounters. Our results are therefore in some ways very similar to that of Garcia \& Koelling (1966), since birds seem to link taste and colour in a way that might help them avoid toxic prey in nature. Potentially this can be seen as an initial stage in the learning process, where birds will more easily associate red and yellow with unpalatability and hence learn more quickly. In fact, no experiment has yet shown that unlearned colour biases lead to improved learning, and psychologists recognize that neophobia and conditioning may be unrelated processes (Braveman \& Jarvis 1978; Miller \& Holzman 1981). However, a more intriguing idea is that unlearned aversions might direct the learning process and may make it easier for birds to associate certain colours with bad taste and toxicity (Rowe \& Guilford 1999b). Rowe (1998) found that if chicks were given a colour discrimination task between green and yellow crumbs, they showed signs of learning the task only when the yellow crumbs were made unpalatable, and not when green was the signal of unpalatability. A similar effect is seen in Lyytinen et al. (2001), where birds learned to discriminate between palatable and unpalatable green food on the basis of an ultraviolet cue but appeared to do so only when this cue signalled palatable food: perhaps other foraging biases exist that constrain the learning abilities of birds? Many psychology experiments use different tastes and colours in a way that treats them as equivalent; our experiments show that specific colourtaste interactions should be considered in the interpretation of their results.

However these biases influence learning, our results indicate that, with regard to the perception of unpalatability, chicks have an unlearned predisposition to change their foraging behaviour away from colours that are most likely to be harmful. One final and important point is that they increasingly did so at higher levels of unpalatability. The shift in the relative colour preference was much greater at higher concentrations of quinine in experiment 1 , indicating that birds can appreciate subtle differences in levels of unpalatability and adjust their attack rates accordingly. If wild birds also bias their probability of eating an insect on the basis of an initial tasting, the costs of palatable mimics on their unpalatable models may be much lower than predicted by models of mimicry (e.g. Speed 1993; Speed \& Turner 1999). It would also allow birds to discriminate between automimics (where members of the same species have varying levels of toxins), and the palatable cheats in the system would have relatively higher rates of attack than the more unpalatable individuals. How wild birds use taste initially to avoid and learn to avoid prey of different appearances and toxicities is an interesting area for research, and has implications for many of our ideas about the evolution of warning coloration and mimicry.

\section{Acknowledgments}

We thank Michelle Waddle and Lin Hedgecock, who looked after our animals, and Francis Gilbert, Sue Healy and two anonymous referees for their comments on the manuscript. J.S. is supported by a School of Biology Studentship, and C.R. is a Royal Society Dorothy Hodgkin Research Fellow. The study was supported by the BBSRC, the Royal Society and a Wellcome Trust Joint Infrastructure Fund award.

\section{References}

Braveman, N. S. \& Jarvis, P. S. 1978. Independence of neophobia and taste aversion learning. Animal Learning and Behavior, 6, 406-412.

Brower, L. P. 1984. Chemical defence in butterflies. In: The Biology of Butterflies (Ed. by R. I. Vane-Wright \& P. R. Ackery), pp. 109134. London: Academic Press.

Brower, L. P., Ryerson, W. N., Coppinger, L. I. \& Glazier, S. C. 1968. Ecological chemistry and the palatability spectrum. Science, 161, 1342-1381.

Claridge, M. F. 1974. Stridulation and defensive behaviour in the ground beetle, Cychrus caraboides (L.) . Journal of Entomology A, 49, 7-15.

Clarke, J. C., Westbrook, R. F. \& Irwin, J. 1979. Potentiation instead of overshadowing in the pigeon. Behavioural and Neural Biology, 25, 18-29.

Cott, H. B. 1940. Adaptive Coloration in Animals. London: Methuen. 
Cowan, D. P., Reynolds, J. C. \& Gill, E. L. 2000. Reducing predation through conditioned taste aversion. In: Behaviour and Conservation (Ed. by L. M. Gosling \& W. J. Sutherland), pp. 281-299. Cambridge: Cambridge University Press.

Cuthill, I. C., Partridge, J. C., Bennett, A. T. D., Church, S. C., Hart, N. S. \& Hunt, S. 2000. Ultraviolet vision in birds. Advances in the Study of Behaviour, 29, 159-214.

Edmunds, M. 1974a. Defence in Animals. Harlow, Essex: Longman.

Edmunds, M. 1974b. Significance of beak marks on butterfly wings. Oikos, 25, 117-118.

Fischer, G. J., Morris, G. L. \& Ruhsam, J. P. 1975. Color pecking preferences in white leghorn chicks. Journal of Comparative and Physiological Psychology, 88, 402-406.

Franchina, J. J., Moon, C. \& Peters, S. 1997. Effects of toxin magnitude on taste aversion and taste-potentiated aversion to visual cues in chicks (Gallus domesticus). Physiology and Behavior, 62, 605-609.

Gamberale-Stille, G. \& Tullberg, B. S. 2001. Fruit or aposematic insect? Context-dependent colour preferences in domestic chicks. Proceedings of the Royal Society of London, Series B, 268, 25252529.

Garcia, J. \& Koelling, R. A. 1966. Relation of cue to consequence in avoidance learning. Psychonomic Science, 4, 123-124.

Gittleman, J. \& Harvey, P. H. 1980. Why are distasteful prey not cryptic? Nature, 286, 149-150.

Guilford, T. 1992. The evolution of aposematism. In: Insect Defenses (Ed. by D. L. Evans \& J. O. Schmidt), pp. 23-61. Albany: State University of New York Press.

Haskell, P. J. 1966. Insect Sounds. London: Witherby.

Hayne, H., Rovee-Collier, C., Collier, G., Tudor, L. \& Morgan, C. A. 1996. Learning and retention of conditioned aversions by freely feeding chicks. Developmental Psychobiology, 29, 417-431.

Jetz, W., Rowe, C. \& Guilford, T. 2001. Non-warning odors trigger innate color aversions: as long as they are novel. Behavioral Ecology, 12, 134-139.

Jones, R. B. \& Carmichael, N. L. 1998. Pecking at string by individually caged, adult laying hens: colour preferences and their stability. Applied Animal Behaviour Science, 60, 11-23.

Kassarov, L. 1999. Are birds able to taste and reject butterflies based on 'beak mark tasting'? A different point of view. Behaviour, 136, 965-981.

Lett, B. T. 1980. Taste potentiates color-sickness associations in pigeons and quail. Animal Learning and Behavior, 8, 193-198.

Lindström, L., Rowe, C. \& Guilford, T. 2001. Pyrazine odour biases food selection in avian predators against conspicuously coloured prey. Proceedings of the Royal Society of London, Series B, 268, 357361.

Lyytinen, A., Alatalo, R. V., Lindström, L. \& Mappes, J. 2001. Can ultraviolet cues function as aposematic signals? Behavioral Ecology, 12, 65-70.

Marples, N. M. \& Roper, T. J. 1996. Effects of colour and smell on the response of naïve chicks towards food and water. Animal Behaviour, 51, 1417-1424.

Marples, N. M., van Valen, W. \& Brakefield, P. M. 1994. The relative importance of colour, taste and smell in the protection of an aposematic insect Coccinella septempunctata. Animal Behaviour, 48, 967-974.

Mastrota, F. N. \& Mench, J. A. 1995. Color avoidance in northern bobwhites: effects of age, sex and previous experience. Animal Behaviour, 50, 519-526.

Miller, R. R. \& Holzman, A. D. 1981. Neophobia: generality and function. Behavioral and Neural Biology, 33, 17-44.

Möstler, G. 1935. Beobachtungen zur Frage der Wespenmimikry. Zeitschrift für Morphologie und Ökologie der Tiere, 29, 381-454.
Nishida, R. 2002. Sequestration of defensive substances from plants by Lepidoptera. Annual Review of Entomology, 47, 57-92.

Poulton, E. B. 1890. The Colours of Animals. Their Meaning and Use. Especially Considered in the Case of Insects. London: Kegan Paul, Trench, Trübner.

Roper, T. J. 1990. Responses of domestic chicks to artificially coloured insect prey: effects of previous experience and background colour. Animal Behaviour, 39, 466-473.

Roper, T. J. \& Cook, S. E. 1989. Responses of chicks to brightly coloured insect prey. Behaviour, 110, 276-293.

Roper, T. J. \& Marples, N. M. 1997a. Odour and colour as cues for taste-avoidance learning in domestic chicks. Animal Behaviour, 53 , 1241-1250.

Roper, T. J. \& Marples, N. M. 1997b. Colour preferences of domestic chicks in relation to food and water presentation. Applied Animal Behaviour Science, 54, 207-213.

Roper, T. J. \& Wistow, R. 1986. Aposematic coloration and avoidance learning in chicks. Quarterly Journal of Experimental Psychology, 38B, 141-149.

Rothschild, M., Moore, B. P. \& Brown, W. V. 1984. Pyrazines as warning odour components in the monarch butterfly, Danaus plexippus, and in moths of the genera Zygena and Amata (Lepidoptera). Biological Journal of the Linnean Society, 23, 372380.

Rowe, C. 1998. Multicomponent signals. Ph.D. thesis, University of Oxford.

Rowe, C. 2002. Sound improves visual discrimination learning in avian predators. Proceedings of the Royal Society of London, Series $B$, 269, 1353-1357.

Rowe, C. \& Guilford, T. 1996. Hidden colour aversions in domestic chicks triggered by pyrazine odours of insect warning signals. Nature, 383, 520-522.

Rowe, C. \& Guilford, T. 1999a. Novelty effects in a multimodal warning signal. Animal Behaviour, 57, 341-346.

Rowe, C. \& Guilford, T. 1999b. The evolution of multimodal warning displays. Evolutionary Ecology, 13, 655-671.

Schuler, W. \& Hesse, E. 1985. On the function of warning coloration: a black and yellow pattern inhibits prey attack by naïve domestic chicks. Behavioral Ecology and Sociobiology, 16, 249-256.

Schuler, W. \& Roper, T. J. 1992. Responses to warning coloration in avian predators. Advances in the Study of Behaviour, 21, 111-146.

Shettleworth, S. J. 1972. The role of novelty in learned avoidance of unpalatable 'prey' by domestic chicks (Gallus gallus). Animal Behaviour, 20, 29-35.

Sillén-Tullberg, B. 1985. The significance of coloration per se, independent of background, for predator avoidance of aposematic prey. Animal Behaviour, 33, 1382-1384.

Smith, D. A. S. 1979. The significance of beak marks on the wings of an aposematic butterfly. Nature, 281, 215-216.

Speed, M. 1993. Muellerian mimicry and the psychology of predation. Animal Behaviour, 45, 571-580.

Speed, M. \& Turner, J. R. G. 1999. Learning and memory in mimicry. Il. Do we understand the mimicry spectrum? Biological Journal of the Linnean Society, 67, 281-312.

Steiniger, F. 1937. 'Ekelgeschmack' und visuelle Anpassung einiger Insekten. Zeitschrift für Wissenschaftliche Zoologie, 149, 221-229.

Testa, T. J. \& Ternes, J. W. 1970. Specificity of conditioning mechanisms in the modification of food preferences. In: Learning Mechanisms in Food Selection (Ed. by L. M. Barker, M. R. Best \& M. Domjan), pp. 229-253. Waco, Texas: Baylor University Press.

Westbrook, R. F., Clarke, J. C. \& Provost, S. 1980. Long-delay learning in the pigeon: flavor, color, and flavor-mediated color aversions. Behavioural and Neural Biology, 28, 398-407. 